\title{
DETERMINAÇÃO DE COLIFORMES TOTAIS E TERMOTOLERANTES EM HAMBÚRGUERES VENDIDOS EM FAST FOODS NA CIDADE DE CURITIBA - PARANÁ
}

\author{
Willian Barbosa SALES ${ }^{1}$ \\ Kamila Christine KUCHAK ${ }^{2}$ \\ Cristiano CAVEIÃO ${ }^{3}$
}

\author{
${ }^{1}$ Biólogo. Especialista em Análises Clínicas. Mestre em Saúde e Meio Ambiente. \\ Doutorando em Saúde e Meio Ambiente. Centro Universitário Autônomo do Brasil - UniBrasil. \\ sallesbio@hotmail.com \\ ${ }^{2}$ Farmacêutica. Centro Universitário Autônomo do Brasil - UniBrasil. Kamilakuchak@gmail.com \\ ${ }^{3}$ Enfermeiro. Mestre em Biotecnologia. Doutorando em Enfermagem. Centro Universitário Autônomo do Brasil - \\ UniBrasil.cristiano_caveiao@hotmail.com
}

Recebido em: 21/12/2015 - Aprovado em: 17/07/2016 - Disponibilizado em: 18/12/2016

\begin{abstract}
RESUMO
Os hambúrgueres produzidos por fast foods contribuem para o aumento de Doenças Transmitidas por Alimento (DTA's), visto que possuem produto de origem cárnea, facilmente suscetível a contaminação caso manipulado incorretamente. O objetivo da presente pesquisa é determinar através de análise microbiológica pelo método de Petrifilm ${ }^{\circledR}$ 3M, a presença de coliformes Totais e Termotolerantes e avaliar a temperatura em hambúrgueres vendidos em fast food na cidade de Curitiba-Paraná, e então comparar os resultados com a RDC 12 de 2 de janeiro de 2001 e RDC 216 de 15 de setembro de 2004 da Agência Nacional de Vigilância Sanitária. Para tanto foram colhidas 10 amostras de hambúrgueres de diferentes estabelecimentos de fast food, e foram aferidas as temperaturas imediatamente e posteriormente foi realizada análise microbiológica. As temperaturas aferidas foram insatisfatórias, estavam entre $30^{\circ} \mathrm{C}$ e $57^{\circ} \mathrm{C}$, abaixo do especificado na RDC $216 / 2004$, que preconiza conservação a quente acima de $60^{\circ} \mathrm{C}$. Por outro lado não se obteve crescimento microbiológico nas placas de Petrifilm® 3M, estando de acordo com a RDC 12/2001. Os resultados obtidos levam a discussão sobre a utilização de quantidades exorbitantes de conservantes, abrindo vertente para novas pesquisas.
\end{abstract}

Palavras-chave: Análise microbiológica. Microbiologia de alimentos. Grupo coliforme. Manipulação de alimentos. Conservação.

\begin{abstract}
The burgers produced by fast foods contribute to the increase in food borne diseases (DTA's) since they are the product of meat origin, easily susceptible to contamination if handled incorrectly. The aim of this research is to determine through microbiological analysis at Petrifilm ${ }^{\circledR} 3 \mathrm{M}$ method, the presence of overall and fecal coliforms and evaluate the temperature in burgers sold in fast food in the city of Curitiba, Paraná, and then compare the results with the DRC 12 of January 2, 2001 and DRC 216 of 15 September 2004 of the National Health Surveillance Agency. Therefore, we collected 10 samples of different burgers fast food establishments, and were measured temperatures immediately and was later performed microbiological analysis. The measured temperatures were unsatisfactory, were between $30^{\circ} \mathrm{C}$ and $57^{\circ} \mathrm{C}$ below the specified DRC $216 / 2004$, which calls hot storage above $60^{\circ} \mathrm{C}$. On the other hand there is as microbiological growth on the boards of Petrifilm ${ }^{\circledR} 3 \mathrm{M}$, which is consistent with the DRC 12/2001. The results lead the discussion on the use of exorbitant amounts of preservatives, opening side for further research.
\end{abstract}

Keywords: Microbiological analysis. Food microbiology. Coliform group. Food handling. Conservation. 


\section{INTRODUÇÃO}

O serviço de fast food vem sendo cada dia mais procurado pela população, principalmente, quem habita os grandes centros urbanos. A industrialização e intensa urbanização foram primordiais para 0 crescimento desta procura, que hoje é impulsionada pelo capitalismo. De acordo com a última Pesquisa de Orçamento Familiar (POF) do Instituto Brasileiro de Geografia e Estatística (IBGE) realizada em 2008-2009, há um aumento no número de estabelecimentos produtores de alimentos prontos e os brasileiros têm gasto em torno de $24 \%$ de suas despesas com alimentação fora do lar, no qual se inclui o fast food. Logo, surge a preocupação com a qualidade higiênico sanitária dos alimentos que são oferecidos a população, tratando-se de um fator crucial para a segurança dos alimentos, pois surtos de Doenças Transmitidas por Alimentos (DTA's) são evidenciadas mundialmente com grande frequência (TAVARES; SERAFINI, 2006; LEAL, 2010; BEZERRA; SICHIERI, 2010; IBGE, 2010; TAKAHASHI et al., 2013).

A Agência Nacional de Vigilância Sanitária (Anvisa), através da RDC n 216, de setembro de 2004, dispõe sobre Boas Práticas para Serviços de Alimentação e preconiza a supervisão e capacitação dos manipuladores periodicamente em higiene pessoal, doenças veiculadas por alimento e manipulação correta dos alimentos (BRASIL, 2004;

TAKAHASHI et al., 2013).

O hambúrguer por se tratar de um produto cárneo, necessita da correta manipulação, pois facilmente pode veicular micro-organismos patógenos. A contaminação deste se dá, principalmente, pelo Staphylococcus Coagulase Positiva, Clostridium Sulfito Redutor, Salmonela spp, Coliformes Totais e Coliformes Termotolerantes (BRASIL, 2001; MELO et al., 2012).

Os Coliformes Totais são bactérias classificadas como bacilos Gram negativos não esporulados, fermentadores de lactose, com produção de gás em faixa de temperatura de $\quad 35^{\circ} \mathrm{C} . \quad \mathrm{O}$ subgrupo, Coliformes Termotolerantes ou Coliformes a $45^{\circ} \mathrm{C}$, conhecido anteriormente como Coliformes Fecais, possuem a mesma definição, porém, como o próprio nome sugere fermentam a lactose e produzem gás a temperatura aproximada de $45^{\circ} \mathrm{C}$ (FRANZ; ALMEIDA, 2002; BRASIL, 2005).

Este grupo de bactérias, os Coliformes, funcionam como indicador na pesquisa em alimentos e água, para constatar a realidade das condições sanitárias e das boas práticas de manipulação e fabricação, pois, seu principal habitat é o trato intestinal de animais homeotérmicos, além do solo e vegetação. $O$ principal representante dos Coliformes Termotolerantes é a Escherichia coli, a qual está normalmente presente nas 
fezes, logo contagens positivas para E.coli representam que a amostra em análise teve contato com material fecal (FRANZ; ALMEIDA, 2002).

Como a grande procura por alimentos servidos em fast foods tem gerado grande preocupação em torno das condições com que estes alimentos são servidos a população, o presente trabalho tem por finalidade evidenciar a possível contaminação, por Coliformes Totais e Termotolerantes, em hambúrgueres vendidos na cidade de Curitiba-PR através do método de Petrifilm ${ }^{\circledR} 3 \mathrm{M}$, e visto que a Anvisa preconiza as Boas Práticas de Fabricação, esta pesquisa também evidencia se os produtos alimentícios, neste caso o hambúrguer, estão em conformidade com os regulamentos técnicos descritos na RDC $\mathrm{n}^{\mathrm{o}} 12$, de 2 de janeiro de 2001 e se estão sendo comercializados em temperatura adequada, conforme a RDC n ${ }^{\circ} 216$ de 15 de setembro de 2004.

\section{MÉTODOS}

Foram compradas 10 (dez) amostras de hambúrguer, de estabelecimentos da região central de Curitiba-PR. As coletas foram realizadas no período de Junho de 2015. Como critérios de inclusão foram avaliados estabelecimentos comerciais fast food, que tem como produto de comercialização hambúrguer bovino, e que estão credenciados pela Prefeitura Municipal de Curitiba pelo setor de Vigilância Sanitária com licença sanitária válida exposta e disponível para visualização no momento da compra. Foram excluídas amostras não preparadas no momento da aquisição e amostras de hambúrguer de carne não bovina.

Após a aquisição, $100 \%$ das amostras tiveram sua temperatura aferida por um termômetro digital tipo espeto da marca (Equitherm), a haste de metal do termômetro foi inserida no centro geométrico do hambúrguer por um minuto, quando foram realizadas a leitura e o registro dos dados, as quais foram identificadas com números de 1 a 10, em seguida foram transportadas na embalagem fornecida pelo estabelecimento, imediatamente ao laboratório de Microbiologia do Centro Universitário Autônomo do Brasil (UniBrasil), para execução das análises, visto que estavam acondicionadas em caixa de material isotérmico, para manter as características microbiológicas.

Foi realizada análise microbiológica através do método de Petrifilm® ${ }^{\circledR} \quad(3 \mathrm{M}$ Company) (Método oficial da Association of Official Analytical Chemists - AOAC), o qual realiza modificações na coloração da placa, composta por dois filmes estéreis reidratáveis, impregnados pelo meio de cultura que contém os nutrientes do ágar vermelho violeta bile (VRBA), um agente gelificante solúvel em água fria, um indicador de atividade 
glucuronidase (5-bromo-4cloro-3indolil- $\beta$-Dglicuronídeo) e um indicador tetrazólico, indicando presença de Unidades Formadoras de Colônia (UFC's) (FERRATI et al., 2005; SILVA, 2010; FORSYTHE, 2013).

Para produção da amostra foi pesada 25 gramas de cada hambúrguer e adicionado $225 \mathrm{~mL}$ de água peptonada estéril. Após a amostra foi devidamente liquidificada e homogeneizada por 01 minutos, foram realizadas diluições seriadas de fator de diluição 10 em três tubos, composta de $9 \mathrm{~mL}$ de água peptonada e $1 \mathrm{~mL}$ da amostra, obtendo diluições de $1 / 10,1 / 10^{2}$ e $1 / 10^{3}$. A partir da terceira diluição, com o auxílio de pipeta, foi inoculado $1 \mathrm{~mL}$ no filme inferior da placa de Petrifilm ${ }^{\circledR}$, e recoberto com o filme superior. Após a solidificação do gel, as placas foram incubadas em $35^{\circ} \mathrm{C}$ por 48 horas para o desenvolvimento das colônias. Todo o material utilizado para o processamento das amostras estava estéril e toda a operação foi realizada próximo a um bico de Bunsen com a chama a meia altura em uma câmara de fluxo laminar (OLIVEIRA, 2006; SILVA, 2010; SOBRINHO et al., 2012; FORSYTHE, 2013; SILVA; CAVALLI; MENEZES, et al., 2014).

$$
\text { Para interpretação da placa e }
$$
determinar a presença de Coliformes Totais e Termotolerantes nas amostras, foi realizado a contagem das UFC's, onde o aparecimento de coloração vermelho escuro no gel ocorreu devido ação do ácido no indicador de $\mathrm{pH}$ e produção de gás retido ao redor das colônias vermelhas é característico da presença de coliformes totais. Para os coliformes termotolerantes (Escherichia coli) a característica da colônia é azul ou vermelhaazulada associada a bolhas de gás, que ocorre devido a glicoronidase produzida pela Escherichia coli reagir com o corante indicador na placa, formando um precipitado azul em torno da colônia. Não foram consideradas e contadas colônias que crescerem na borda de espuma da placa, pois estas não estavam sob a influência seletiva do meio (SILVA, 2010; FORSYTHE, 2013).

Os resultados foram registrados e analisados de forma descritiva simples, através de um banco de dados elaborado com auxílio do programa Microsoft EXCEL ${ }^{\circledR}$. Os resultados das análises microbiológicas foram avaliados de acordo com a RDC 12/2001 e comparados as condições sanitárias com presença ou ausência dos micro-organismos pesquisados e avaliado a temperatura no momento da comercialização, conforme o que preconiza a RDC 216/2004.

\section{RESULTADOS E DISCUSSÃO}

Os resultados das análises microbiológicas no presente estudo apresentaram ausência de Coliformes Totais e Termotolerantes. No entanto a análise das temperaturas aferidas no momento da compra, indica que o produto não estava sendo 
comercializado de forma correta conforme figura 1.

Figura 1 - Temperatura aferida em hambúrgueres imediatamente após aquisição em fast foods na cidade de Curitiba-PR.

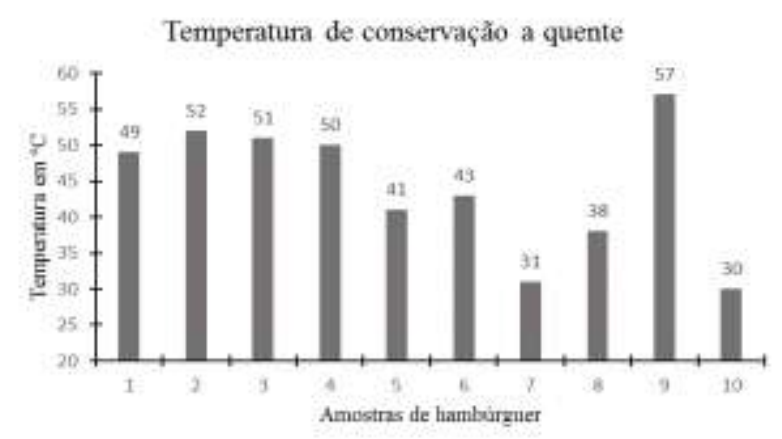

Fonte: O autor, 2015.

Considerando a temperatura, os resultados obtidos foram insatisfatórios pois todas as temperaturas estavam abaixo do que preconiza a $\mathrm{RDC} \mathrm{n}^{\mathrm{o}} 216$, de 15 de setembro de 2004, para conservação a quente acima de $60^{\circ} \mathrm{C}$. Abaixo também do que determina o Food and Drug Administration (FDA) que todas as partes do hambúrguer devem ser adequadamente cozidas, principalmente suas porções mais frias (geralmente o centro geométrico), utilizando temperaturas internas de no mínimo $68^{\circ} \mathrm{C}$ por 15 segundos (BRASIL, 2004; EUA, 2013).

Contudo não se obteve crescimento de UFC's de Coliformes totais e Termotolerantes mesmo com a condição inadequada de suas temperaturas conforme as legislações, estando de acordo com a RDC 12/2001, que preconiza ausência desses micro-organismos no produto. No entanto embora o mesmo se encontre adequado ao consumo humano conforme a RDC 12/2001, o parâmetro das temperaturas aferidas no momento da compra indica um produto inadequado para o consumo humano conforme a legislação vigente dos valores referentes a temperatura de comercialização (BRASIL, 2001; BRASIL, 2004).

Em estudo realizado por Antunes (2005), relata que os principais erros cometidos durante a preparação de alimentos e que levam ao desenvolvimento de DTA's, estão principalmente a temperatura de armazenamento, o intervalo de tempo entre o preparo e o consumo, a temperatura insuficiente durante o período de cozimento do alimento que acabam favorecendo o crescimento de patógenos, e ainda ressalta o despreparo de manipuladores com falta de higiene básica e ainda contaminação cruzada.

Do mesmo modo, Silva Jr. (2002), destaca que os pontos críticos para controle de produtos cárneos, ou seja, de maior risco de contaminação, são as etapas que necessitam ser realizadas manualmente, o corte da matéria prima, adição de ingredientes e cocção atingindo a temperatura adequada.

Estudo realizado por Cielask et al. (1997) realizaram uma pesquisa em hambúrgueres de fast food da região de Las Vegas (EUA), e constatou divergência entre tempo e temperatura de cozimento necessário, que foi responsável por surto de contaminação por E. Coli. Tavares (2006) 
também afirma que hambúrguer malcozido é um dos principais fatores que levam ao surto de contaminação por E. Coli e infecções esporádicas.

Fica claro que a contaminação cruzada e a falta de tratamento térmico em produtos cárneos estão diretamente ligadas a surtos de DTA's carreados por hambúrgueres, o que ressalta a importância do controle da temperatura para avaliar a possibilidade de morte ou sobrevivência de micro-organismos na cocção e reaquecimento e se há risco de multiplicação durante o período de armazenamento dos alimentos prontos para consumo. Pesquisas revelam diminuições consideráveis nas concentrações de E. Coli e Salmonella sp em hambúrgueres que foram corretamente submetidos ao cozimento com temperatura adequada. E ainda foram totalmente inativas quando a temperatura interna de cozimento atingiu $71^{\circ} \mathrm{C}$ (SALMON et al., 2000).

Segundo Sales, Schweigert e Ravazzani (2015), verificou a temperatura e o crescimento de UFC's de Coliformes Totais e Termotolerantes de amostras de carne bovina moída, e constatou uma relação entre a alta temperatura no momento da comercialização e a contagem positiva de Coliformes Totais. No entanto os resultados verificados na presente pesquisa não apresentam a mesma relação, levando a considerar o uso de aditivos de conservação em hambúrgueres.
O uso de aditivos alimentares tornouse frequente, afim de promover diversas funções no produto final. A RDC $\mathrm{n}^{\circ} 540$ de 27 de outubro 1997, define aditivo alimentar como qualquer ingrediente adicionado aos alimentos sem o propósito de nutrir e com o objetivo de modificar características sensoriais, biológicas, físicas ou químicas, durante $\mathrm{o}$ processamento, tratamento, embalagem, acondicionamento, transporte ou manipulação, no qual se destaca os aditivos conservadores que possuem a função de retardar ou impedir a alteração dos alimentos causadas por micro-organismos. No entanto, a RDC 540/1997, deixa claro a proibição do uso de aditivos em casos onde sua função seja encobrir falhas no processamento e/ou nas técnicas de manipulação (BRASIL, 1997; BRASIL, 1998; CUNHA et al., 2003; SILVA et al., 2009).

$\mathrm{Na}$ indústria de carnes o principal aditivo de conservação utilizado é o nitrito. Contudo seu uso é restringido pois o excesso de nitrito residual no produto final pode causar intoxicações, assim como a formação de nitrosaminas, compostos cancerígenos, geradas a partir da reação entre nitrito em excesso e aminas da carne (DAGUER, 2005). Estudo realizado por Cunha et al. (2003), afirma que, dentre os produtos de origem cárnea, mortadelas, linguiças e salsichas apresentam concentrações de nitrito residual superior ao preconizado pela legislação vigente, que é de $0,015 \mathrm{~g} / 100 \mathrm{~g}$. 
Em estudo realizado por Scheibler, Marchi e Souza (2013), em linguiça artesanal no Vale do Taquari - RS para determinar os teores de nitrito e nitrato e constatou que das 16 amostras coletadas $37,5 \%$ apresentavam valores superiores de nitratos de nitritos em relação ao estabelecidos pela legislação. Silva et al. (2009) avaliou a adição de nitrito e sulfito e o grau de depleção do nitrito pós cocção em carnes bovinas moídas in natura e resfriadas, comercializadas em mercados do estado do Rio de Janeiro. Com a obtenção dos resultados pode constatar a prática fraudulenta de adição de conservantes, nitrito e sulfito, em carnes in natura, descumprindo a legislação vigente por parte dos comerciantes, pois das 35 amostras $37,14 \%$ apresentaram nitrito e $11,42 \%$ sulfito e ainda $17,14 \%$ apresentaram odor desagradável na prova de cocção.

\section{CONCLUSÃO}

Avaliando os resultados da presente pesquisa, em relação aos valores obtidos após a aferição da temperatura, é possível concluir que todas as amostras se encontram fora dos parâmetros preconizados pela ANVISA e pelo FDA, não estando adequadas para o consumo humano. Contudo não houve crescimento de UFC's de Coliformes Totais e Termotolerantes para nenhuma das amostras, estando de acordo com a RDC 12/2001. A incoerência dos valores obtidos entre os fatores, temperatura de conservação a quente, quando comparado ao crescimento microbiológico, levantam suspeita a respeito do uso indevido de aditivos de conservação pelas indústrias produtoras de hamburguês.

Portanto a realização de testes físicoquímicos de identificação de conservantes em hambúrgueres de fast food, determinariam maior clareza e conformidade na avaliação comparativa entre os resultados obtidos nesta e demais pesquisas realizadas em alimentos de origem cárnea, além de auxiliar na verificação da qualidade do hambúrguer, para garantir que este está sendo oferecido, sem contaminação microbiológica e sem adição em excesso de aditivos de conservação, a fim de não comprometer a saúde do consumidor.

\section{REFERÊNCIAS}

ANTUNES, F. Relação entre a ocorrência de diarreia e surtos alimentares em Curitiba-PR. Universidade Federal do Paraná. Curitiba, 2005.

BEZERRA, I. N.; SICHIERI, R.

Características e gastos com alimentação fora do domicúlio no Brasil. Revista Saúde

Pública, São Paulo, v.44, n.2, p.221-229, 2010.

BRASIL. Ministério da Saúde. Agência Nacional de Vigilância Sanitária (ANVISA). Portaria n ${ }^{\circ} 540$, de 27 de outubro de 1997.

Regulamento Técnico: Aditivos Alimentares - definições, classificação e emprego. Diário Oficial da República Federativa do Brasil. Brasília: DF, 1997.

BRASIL. Ministério da Saúde. Agência Nacional de Vigilância Sanitária (ANVISA). Portaria $\mathrm{n}^{\circ} 1.004$, de 11 dezembro 1998. 
Regulamento Técnico: Atribuição de função de aditivos, aditivos e seus limites máximos de uso para a categoria 8 - carne e produtos cárneos. Diário Oficial da República Federativa do Brasil. Brasília: DF, 1998.

BRASIL. Ministério da Saúde. Agência Nacional de Vigilância Sanitária (ANVISA). Resolução RDC n $^{\circ} 12$, de 02 de janeiro de 2001. Regulamento Técnico sobre padrões microbiológicos para alimentos. Diário Oficial da República Federativa do Brasil. Brasília: DF, 2001.

BRASIL. Ministério da Saúde. Agência Nacional de Vigilância Sanitária (ANVISA). Resolução RDC ${ }^{\circ}{ }^{\circ} 216$, de 15 de setembro de 2004. Regulamento Técnico de Boa Práticas para Serviços de Alimentação. Diário Oficial da República Federativa do Brasil. Brasília: DF, 2004.

BRASIL. Conselho Nacional do Meio Ambiente (CONAMA). Resolução n ${ }^{\circ} 357$, de 17 de Março de 2005. Classificação dos corpos de água e diretrizes ambientais para o seu enquadramento, bem como estabelece as condições e padrões de lançamento de efluentes, e dá outras providências. Diário Oficial da República Federativa do Brasil. Brasília: DF, 2005.

BRASIL. Ministério do Planejamento, Orçamento e Gestão - Instituto Brasileiro de Geografia e Estatística - IBGE. Pesquisa de orçamentos familiares 2008-2009: despesas, rendimento e condições de vida. Rio de Janeiro: RJ, 2010.

CIESLAK, P. R.; NOBLE, S. J.; MAXSONI, D. J.; EMPEY, L. C.; RAVENHOLT, O.; LEGARZA, G, et al. Hamburger-associated Escherichia coli O157:H7 infection in Las Vegas: a hidden epidemic. American Journal of Public Health, v.87, n.2, p.176180, 1997.

CUNHA, F. A.; CARVALHO, T. M. J. P.; MENEZES, E. A.; OLIVEIRA, M. S. C.;
SOUZA, P. A. S.; PEREIRA, A. F, et al. Determinação de nitritos em alimentos cárneos. Revista Brasileira de Análises Clínicas, v.35, n.1, p.3-4, 2003.

DAGUER, H. A cura da carne e a formação de nitrosaminas. Higiene Alimentar, v.19, n.134, p.15-20, 2005.

FRANZ, R. N.; ALMEIDA, J. A. G. Teste alternativo para detecção de coliformes em leite humano ordenhado. Jornal de Pediatria, v.78, n.3, p.193-196, 2002.

FERRATI, A. R.; TAVOLARO, P.; DESTRO, M. T.; LANDGRAF, M.; FRANCO, B. D. G. M. A Comparison of ready-to-use systems for evaluating the microbiological quality of acidic fruit juices using non-pasteurized orange juice as an experimental model. International Microbiology, v.8, n.1, p.48-53, 2005.

FORSYTHE, J. S. Microbiologia da Segurança dos Alimentos. Porto Alegre (RS): Artmed, 2013.

LEAL, D. Crescimento da alimentação fora do domicílio. Segurança alimentar e nutricional, v.17, n.1, p.123-132, 2010.

MELO, L. F.; VILELA, N. A.; CARVALHO, P. L. N.; VEIGA, S. M. O. M.;

NASCIMENTO, L.C. Qualidade higiênico sanitária da carne de hambúrguer industrializada. Revista da Universidade Vale do Rio Verde, v.10, n.2, p.370-375, 2012.

MENEZES, A. C.; ALEXANDRINO, A. M. Análise microbiológica de hambúrgueres comercializados em embalagens primárias e secundárias. SaBios-Revista de Saúde e Biologia, v.9, n.3, p.94-100, 2014.

SALMON, C.P.; KNIZE, M. G.; PANTELEAKOS, F. N.; WU, W. R.; NELSON, O. D.; FELTON, S. J. Minimization of heterocyclic amines and thermal inactivation of Escherichia coli in 
fried ground beef. Journal of the National Cancer Institute, v.92, n.21, p.1773-1778, 2000.

SCHEIBLER, J. R.; MARCHI, M. I.; SOUZA, C. F. V. Análise dos teores de nitritos e nitratos de embutidos produzidos em municípios do vale do taquari-rs. Revista destaques acadêmicos, v.5, n.4, p.201-207, 2013.

SALES, W. B.; SCHWEIGERT, M. L.; RAVAZZANI, E. D. A. Avaliação da qualidade higienicossanitária da carne bovina. Higiene Alimentar, v. 29, n.246/247, p.9397, 2015.

SILVA-JUNIOR, E. A. Manual de Controle Higiênico-Sanitário em Alimentos. São Paulo (SP): Livraria Varela, 2002.

SILVA, M. P.; CAVALLI, D. R.; OLIVEIRA, T. C. R. M. Avaliação do padrão coliformes a $45^{\circ} \mathrm{C}$ e comparação da eficiência das técnicas dos tubos múltiplos e Petrifilm EC na detecção de coliformes totais e Escherichia coli em alimentos. Ciência Tecnologia Alimentos, v.26, n.2, p.352-359, 2006.

SILVA, C.; MONTEIRO, M. L. G.; RIBEIRO, R. O. R.; GUIMARÃES, F. M.; MANO, S. B.; PARDI, H. S, et al. Presença de aditivos conservantes (nitrito e sulfito) em carnes bovinas moídas, comercializadas em mercados varejistas. Revista Brasileira de Ciências Veterinárias, v.16, n.1, p.33-36, 2009.

SILVA, N. Manual de Métodos de análise Microbiológica de Alimentos e Água. São Paulo (SP): Varela; 2010.

SOBRINHO, P. S. C.; FARIA, C. A. M.; PINHEIRO, J. S.; ALMEIDA, H. G.; PIRES, C. V.; SANTOS, A. S. Bacteriological Quality of Raw Milk Used for Production of a Brazilian Farmstead Raw Milk Cheese.

Foodborne Pathogens and disease, v.9, n.2, p.138-144, 2012.

TAVARES, T. M.; SERAFINI, A. B. Carnes de hambúrgueres prontas para consumo: aspectos legais e riscos bacterianos. Revista de Patologia Tropical, v.35, n.1, p.1-21, 2006.

TAKAHASHI, C. C.; AMARAL, P. E.; SANTOS, L. C. L.; CONTIM, J. D.; PINTO, U. M.; NEVES, C. V. B, et al. Avaliação do treinamento de manipuladores de alimento de restaurantes comerciais pelo ensaio ATPbioluminescência. Revista Adolfo Lutz, v.72, n.4, p.302-308, 2013.

UNITED STATES OF AMERICA.

Department of health and human services. Food Code. Public Health Service - Food and Drug Administration. Washington, DC: USA, 2013. 